\title{
DIREITO À SAÚDE E OS PROBLEMAS DO DISCURSO CONSEQUENCIALISTA
}

\author{
RIGHT TO HEALTH AND THE PROBLEMS \\ OF CONSEQUENTIALIST DISCOURSE
}

\author{
ILTON GARCIA DA COSTA ${ }^{1}$ \\ ANTONIO CYRO VENTURELLI ${ }^{2}$
}

\section{RESUMO}

O direito à saúde está assegurado na Constituição da República de 1988 como um dos direitos fundamentais do ser humano, sendo dever do Estado garanti-lo através da execução de políticas públicas, consubstanciadas no denominado mínimo vital. Todavia, a aplicação, errônea, da teoria da reserva do possível, para esse fim, produz um vínculo entre a efetivação dos direitos e a capacidade financeira do Estado. A EC 95/2016 implementou o denominado teto de gastos. Não bastasse a adoção enviesada da mencionada teoria e da questão orçamentária, a recente alteração legislativa à LINDB passou a exigir, na esfera judicial, que o magistrado aponte as consequências práticas de sua decisão. Em razão disso, o presente estudo, através do método dialético, partiu do seguinte problema: é dado aos juízes entrever um leque completo das consequências possíveis resultantes de sua decisão, perfazendo-se um verdadeiro exercício de futurologia? Conclui-se que houve, a bem da verdade, uma flagrante tentativa de mitigação da força normativa dos princípios, com o objetivo inconfessável de frear o ativismo judicial.

PALAVRAS-CHAVE: Direito à saúde. Mínimo existencial. Reserva do possível. LINDB. Consequencialismo.

\section{ABSTRACT}

The right to health is affirmed in the Constitution of the Republic of 1988 as one of the fundamental rights of the human being, being the duty of the State to guarantee it through the execution of public policies, embodied in the so-called vital minimum. However, the erroneous application of the theory of the reserve of the possible for this purpose produces a link between the realization of rights and the financial capacity of

1 Professor do Programa de Doutorado, Mestrado e Graduação em Direito da UENP - Universidade Estadual do Norte do Paraná, Doutor e Mestre em Direito pela PUC-SP, Avaliador de IES e Curso do MEC INEP, Membro do Comitê de Área da Fundação Araucaria de Apoio a Pesquisa do Estado do Paraná, líder do Grupo de Pesquisa em Constitucional, Educacional, Relações de Trabalho e Organizações Sociais - GPCERTOS da UENP, Mestre em Administração pelo UNIBERO, ex Vice Presidente da Comissão de Ensino Jurídico da OAB SP, ex Presidente da Comissão de Estágio da OAB SP, membro da Comissão de Direito Constitucional e Com. de Liberdades Religiosas, ex Diretor de Planejamento e Controles de Banco, Especialista em Formação Profissional - Alemanha, Especialista em Finanças, Matemático, Advogado. ORCID iD: http://orcid.org/00000002-0093-161X. E-mail: iltoncosta@uenp.edu.br e iltongcosta@gmail.com.

2 Mestrando em Ciência Jurídica pela Universidade Estadual do Norte do Paraná - UENP; Especialização em Direito Constitucional; graduação em Direito e em Administração de Empresas, é professor de Direito Civil do curso de Direito da Faculdade Eduvale - Avaré, é Chefe de Seção Judiciário $2^{\circ}$ Ofício da Comarca de Piraju/SP servidor do Tribunal de Justiça do Estado de São Paulo - TJSP cyrotjsp@gmail.com. 
the state. EC 95/2016 implemented the so-called spending cap. Not only was the skewed adoption of the aforementioned theory and the budget issue sufficient, the recent legislative amendment to the LINDB now required the magistrate to point out the practical consequences of his decision. Because of this, the present study, through the dialectical method, started from the following problem: Are judges given a full range of possible consequences resulting from their decision, making a real exercise in futurology? In conclusion, there was, in fact, a flagrant attempt to mitigate the normative force of the principles, with the unmistakable objective of curbing judicial activism.

KEY WORDS: Right to health. Existential minimum. Reservation of the possible. LINDB. Consequentialism.

\section{INTRODUÇÃO}

A Constituição Federal de 1988 tem como um dos seus princípios fundamentais a dignidade da pessoa humana (art. $1^{\circ}$, III). Ao tratar dos direitos e garantias fundamentais dispõe-se que são direitos sociais, dentre outros, o direito à saúde (art. $\left.6^{\circ}\right)$. Diz mais ainda que a saúde é direito de todos e dever do Estado (art. 196 e 197) (BRASIL, 1988).

A estrutura tridimensional das normas constitucionais está disposta em três círculos concêntricos. No primeiro, tem-se o denominado "núcleo essencial" - que consiste no princípio da aplicabilidade imediata (art. $5^{\circ}, \S 1^{\circ}$, da CF/88). Depois, a chamada "parte ponderável" - que abarca o princípio da concordância prática ou da proporcionalidade. Por fim, a "área metajurisdicional" - caracterizada pelo princípio da separação de poderes.

Observa-se que a ponderação é o processo pelo qual se resolverá a tensão entre princípios contrapostos. Com rigor, existem dois caminhos muito bem definidos como resultado de um processo ponderativo, sendo: a) a ponderação harmonizante, que busca conciliar os princípios em tensão, mediante a aplicação da concordância prática (concessões recíprocas dos valores em colisão); e, b) a ponderação excludente que escolhe um princípio vencedor, com sacrifício dos demais princípios em conflito, mediante a aplicação do princípio da proporcionalidade.

No que tange a essa ponderação excludente, há de se aplicar a tríade subprincipal, que envolve a adequação, a necessidade e a proporcionalidade em sentido estrito. Em uma colisão de direitos, a aplicação dessa tríade dar-se-ia nos seguintes termos: i) Analisar a possibilidade da medida levar à realização pretendida (adequação); ii) A medida tem que ser a menos restritiva aos direitos e interesses envolvidos (necessidade); e, iii) A finalidade pública buscada a ponto de justificar a restrição imposta (proporcionalidade em sentido estrito).

O desafio do jurista do século XXI é justamente emprestar cientificidade às teorias da argumentação jurídica, de modo a respaldar as decisões judiciais que inovam a ordem jurídica. Portanto, o grande dilema do juiz hodierno será sempre o enquadramento da sua norma-decisão: núcleo essencial, zona de ponderação de valores ou espaço normativo metajurisdicional (GOES, 2018, p. 166).

O artigo tem por objetivo discorrer sobre os princípios da aplicabilidade imediata (mínimo existencial) e da concordância prática ou da proporcionalidade (reserva do possível), ante às possibilidades e limitação da atuação do Estado no cumprimento do direito à saúde e no fornecimento de medicamentos, que está "subordinado" à existência de recursos públicos 
disponíveis, aí se incluindo a atuação do Poder Judiciário, levando-se em consideração a EC 95/2016 e as recentes alterações na LINDB, com o advento da Lei n. ${ }^{\circ} 13.655$, de 25 de abril de 2018 , notadamente, quanto ao art. 20 , que obriga o magistrado, no âmbito da esfera judicial, a considerar as "consequências práticas" de sua decisão.

\section{O MÍNIMO VITAL}

As teorias do núcleo essencial envolvem a capacidade de gerar um direito subjetivo de per si, sem depender de um processo de ponderação de valores, nem de atuação superveniente do legislador democrático, podendo, tudo superar, o que inclui as reservas do possível, fática e jurídica, e a própria dificuldade contramajoritária do poder judiciário.

A teoria dos direitos fundamentais sociais, atualmente, hospeda uma crescente discussão em torno do que se convencionou chamar de mínimo vital. Essa teoria impõe a preservação material do ser humano, assegurando-Ihe condições mínimas para a preservação da vida e para a integração da sociedade como uma questão prejudicial às políticas públicas a serem desenvolvidas pela governança estatal. 0 texto constitucional claramente se orienta nesse sentido, como por exemplo: ao fixar como um dos seus objetivos a cidadania, a erradicação da pobreza e a diminuição das desigualdades sociais. (NUNES JUNIOR, 2009, p. 71)

Oportuna a transcrição dos dizeres de Ingo Wolfgang Sarlet acerca dos direitos fundamentais sociais:

[...] cremos ser possível afirmar que os direitos fundamentais - de modo particular os sociais - não constituem mero capricho, privilégio ou liberalidade (...) no contexto de um constitucionalismo dirigente "fracassado e superado", mas sim, premente necessidade, já que a sua desconsideração e ausência de implementação fere de morte os mais elementares valores da vida e da dignidade da pessoa humana, em todas as suas manifestações, além de conduzir - tal como com lucidez adverte Paulo Bonavides - a uma lamentável, mas cada vez menos contornável e controlável, transformação de muitos Estados Democráticos de Direito em verdadeiros "estados neocoIoniais". (com destaques acrescentados) (SARLET, 2010, p. 315)

O atendimento a direitos como educação, saúde, alimentação, trabalho, moradia, lazer, segurança, previdência social, proteção à maternidade e à infância e assistência aos desamparados (CF, art. $\left.6^{\circ}\right)$ exige dos poderes públicos, na maior parte dos casos, prestações positivas (direitos de promoção ou direitos prestacionais).

A implementação de tais direitos ocorre mediante políticas públicas concretizadoras de certas prerrogativas individuais e/ou coletivas, destinadas a reduzir as desigualdades sociais existentes e a garantir uma existência humana digna (NOVELINO, 2011, p. 459).

Importa anotar que o STF, após o advento da constituição cidadã, tem se posicionado no sentido de que o Poder Judiciário deve sim, intervir nas políticas públicas, o que pode ser conferido nas explanações de RUSSO e LEHFELD (2016, p. 324):

O Supremo Tribunal Federal vem consolidando o entendimento, principalmente após a promulgação da Constituição Federal de 1.988, no sentido que o Poder Judiciário deve intervir nas políticas públicas com vistas a concre- 
tizar o direito à saúde, com supedâneo nos artigos $6^{\circ}$ e 196 da Carta Magna, no núcleo básico constitucional que qualifica o mínimo existencial e das legislações ordinárias em consonância com a reserva do possível. (RUSSO; LEHFELD, 2016, p. 324).

No mesmo sentido, os dizeres de Bruna Geovana Fagá Tiessi e Ilton Garcia da Costa:

Nesse contexto, o mínimo existencial passou a ser estudado levando-se em consideração à própria questão da pobreza e das condições mínimas de existência digna. Daí entender-se que não há possibilidade de se efetivar os direitos fundamentais sem que ao mesmo tempo seja resguardado o mínimo necessário a cada indivíduo (TIESSI; COSTA, 2013, p. 174).

\section{A RESERVA DO POSSÍVEL}

A reserva do possível originou-se em 1972, por meio de um julgamento realizado pelo Tribunal Federal Alemão, em uma decisão conhecida como "numerus clausus", estabelecendo que o direito postulado pelo cidadão deve estar sujeito à reserva do possível, em relação à sociedade.

É o que ensina Vidal Serrano Nunes Junior:

A teoria em análise parte do pressuposto de que as prestações estatais estão sujeitas a limites materiais ingênitos, oriundos da escassez de recursos financeiros pelo Poder Público. Logo, a ampliação da rede de proteção social dependeria da existência de disponibilidades orçamentárias para tanto. (NUNES JUNIOR, 2009, p. 172)

Quanto a essa escassez, Ingo Wolfgang Sarlet pontua que:

Já há tempo se averbou que o Estado dispõe apenas de limitada capacidade de dispor sobre o objeto das prestações reconhecidas pelas normas definidoras de direitos fundamentais sociais (...) É justamente em virtude desses aspectos que se passou a sustentar a colocação dos direitos sociais a prestações sob o que se denominou de uma "reserva do possível", que, compreendida em sentido amplo, abrange tanto a possibilidade, quanto o poder de disposição por parte do destinatário da norma. (SARLET, 2010, p. 254)

Como se vê, a teoria da reserva do possível faz referência a orçamentos e recursos, além de observar com razoabilidade, requisitos que o administrador deverá considerar dentro do que é economicamente possível, respeitando os princípios da administração pública.

Constata-se que a existência do princípio do mínimo existencial, combinado com a reserva do possível, requer equilíbrio, em situações onde o Estado tem o dever de garantir o mínimo necessário, e.g., a saúde do cidadão, mas, em contrapartida, não há recursos financeiros suficientes.

Com a escassez de recursos, o Estado se propõe a realizar somente o que está dentro de seus limites orçamentários e ao se deparar com um direito fundamental que possui respaldo no mínimo existencial alega que os recursos disponíveis são finitos. 
Sob o entendimento de que a escusa é inaceitável, resta ao prejudicado tomar as providências cabíveis para garantir seu direito constitucionalmente assegurado, não podendo o Estado apenas esquivar-se do dever, ante à carência de recursos.

\section{O CONFLITO ENTRE OS PRINCÍPIOS DO MÍNIMO EXISTENCIAL E DA RESERVA DO POSSÍVEL, NA CONCRETIZAÇÃO DO DIREITO À SAÚDE}

Não resta dúvida de que o direito à saúde é um dos direitos sociais garantidos pela Constituição Federal (art. 6º 196 e 197), o que significa dizer que deve ser efetivado de maneira ampla e irrestrita pelo Estado.

Nesse sentido, a lição de Marcelo Novelino:

0 atendimento a direito como educação, saúde, alimentação, trabalho, moradia, lazer, segurança, previdência social, proteção à maternidade e à infância e assistência aos desamparados (CF, art. 6. ${ }^{\circ}$ ) exige dos poderes públicos, na maior parte dos casos, prestações positivas (direitos de promoção ou direitos prestacionais). A implementação de tais direitos ocorre mediante políticas públicas concretizadoras de certas prerrogativas individuais e/ ou coletivas, destinadas a reduzir as desigualdades sociais existentes e a garantir uma existência humana digna." (NOVELINO, 2011. p. 525, com destaques acrescentados)

O mínimo existencial abarca os direitos sociais, necessários a uma vida permeada pelos direitos fundamentais inerentes à dignidade da pessoa humana, constitucional e internacionalmente, reconhecidos.

Em face dos princípios do mínimo existencial e da reserva do possível, e a situação financeira do Estado, ocorrem conflitos justamente em situações tais em que o cidadão necessita da assistência para garantir sua saúde, como, e.g., no fornecimento de medicamentos. Esse cidadão, a partir da recusa do Estado em Ihe prestar atendimento, recorre ao Judiciário, buscando a satisfação desse direito.

A partir daí, surgem indagações acerca de uma eventual violação do princípio da separação dos poderes, sob o argumento de que o Judiciário estaria se imiscuindo nas questões afetas ao Executivo. Esse, contudo, não parece ser um argumento factível, à vista da aplicação da doutrina da efetividade. Em que pesem as normas programáticas não possuírem eficácia plena, é induvidoso que elas se prestam a garantir o mínimo existencial, aí se incluindo o dever de "prestar" saúde. Ora, caso o direito à saúde não possa encontrar sua plenitude, de outro lado, compete ao Estado traçar as diretrizes para alcançar o bem comum, o que significa dizer que ele tem o dever de garantir o seu núcleo - leia-se, o direito à vida - razão pela qual, o Judiciário estaria sim, autorizado a determinar ao Executivo o cumprimento desse dever, já que a Constituição da República, a esse respeito, possui densidade normativa suficiente para tanto.

Cabe ao Juiz, quando provocado, prover sentido concreto à lei e comedir a juridicidade do ato administrativo, com o intuito de que este não impugne a consumação da ordem social. 
Todavia, é imperioso debruçar-se sobre a origem do princípio da reserva do possível, a fim de que se possa observar com clareza meridiana que há séria distorção na importação e aplicação do modelo alemão em nosso ordenamento, notadamente quando se tratam de direitos fundamentais.

O argumento da reserva do possível, em seu nascedouro, não atina com direitos integrantes do mínimo vital, como o acesso à assistência à saúde ou à educação básica, mas ao ensino público superior. Esse é o ponto.

Nas palavras de Nunes Junior (2009, p. 172), outra não é a conclusão: "as condições jurídico-positivas nas quais a teoria nasceu não se reproduzem no Brasil."

Na mesma esteira, é o sentir de Ingo Wolfgang Sarlet (2010, p. 255):

[...] não nos parece correta a afirmação de que a reserva do possível seja elemento integrante dos direitos fundamentais, como se fosse parte de seu núcleo essencial ou mesmo como se estivesse enquadrada no âmbito do que se convencionou denominar de limites imanentes dos direitos fundamentais. A reserva do possível constitui, em verdade (considerada toda a sua complexidade), espécie de limite jurídico e fático dos direitos fundamentais, por exemplo, na hipótese de conflitos de direitos, quando se cuidar da invocação - observados sempre os critérios da proporcionalidade e da garantia do mínimo existencial em relação a todos os direitos - da indisponibilidade de recursos com o intuito de salvaguardar o núcleo essencial de outro direito fundamental. (SARLET, 2010, p. 255).

Osvaldo Canela Junior (2011), ao discorrer sobre "O papel do Poder Judiciário na efetivação dos direitos fundamentais sociais", traz a lume o orçamento como instrumento para a realização do Estado social. Não é demais repetir. Em sua visão, o orçamento deve ser supedâneo para a implementação de políticas públicas, e não o contrário. Por mais paradoxal que possa ser, essa é justamente a construção doutrinária formulada pelo exegeta. É o orçamento a serviço do bem-estar social e não como óbice a direitos fundamentais, de aplicabilidade imediata e sem delongas, repelindo, assim, a lógica da aplicação do princípio da reserva do possível. Vale a transcrição:

Constata-se que o fenômeno econômico tem sido invocado para impedir a concessão de direitos fundamentais sociais pelo Poder Judiciário. Alega-se, em geral, que o Poder Judiciário não pode conceder direitos cuja satisfação demandará receitas não disponíveis pelo Estado. Tal fundamento, contudo, traz em si a desconsideração de que o Estado brasileiro possui objetivos a serem efetivamente atendidos de tal forma que o orçamento há de servir como instrumento para a respectiva realização, e não como óbice. Com efeito, um dos argumentos mais utilizados para justificar a ausência de efetividade dos direitos fundamentais sociais é o seu impacto econômico-financeiro. A percepção de que a satisfação dos bens da vida protegidos pelos direitos fundamentais sociais causa vinculação econômica no orçamento do Estado suscitou o tema da "reserva do possível", amplamente difundido na doutrina e na jurisprudência, a ponto de ser utilizado como justificativa para eventual inércia do Poder Judiciário na tutela daqueles direitos. (CANELA JUNIOR, 2011, p. 102)

E arremata, com severa crítica à teoria da reserva do possível, expondo que a fundamentação dos argumentos de seus defensores está calcada sob a égide de um Estado liberal, distante do que preconiza a Constituição brasileira de 1988: 
Verifica-se, pois, que a teoria da "reserva do possível" traz em si o espírito estritamente liberal - ou neoliberal -, incompatível com a realidade da Constituição brasileira, porquanto pretende uma inatingível estabilidade orçamentária, afastada dos postulados programáticos do Estado social. (...) 0 pressuposto da "reserva do possível", ao considerar o orçamento como peça estanque de equilíbrio econômico-financeiro, desalinha-se da realidade principiológica do Estado social, causando a paralisação da atividade jurisdicional, em conduta que se mostra frontalmente contrária ao disposto no art. $3^{\circ}$ da Constituição Federal. (Ibid, p. 108-111)

Nesse passo, quando há conflito de princípios entre si um não derroga o outro, mas sim deve ser feita a sua ponderação, por meio da análise da proporcionalidade, conforme se extrai dos apontamentos de Robert Alexy:

Princípios são mandamentos de otimização em face das possibilidades jurídicas e fáticas. A máxima da proporcionalidade em sentido estrito, ou seja, exigência de sopesamento, decorre da relativização em face das possibilidades jurídicas. (...) Isso significa, por sua vez, que a máxima da proporcionalidade em sentido estrito é deduzível do caráter principiológico das normas de direitos fundamentais. (ALEXY, 2008. p. 117-118)

Demais disso, o STJ (Resp 1.657.156-RJ) fixou requisitos para que o Judiciário possa examinar as demandas que pleiteiam o fornecimento de medicamentos que não constam do anexo I da Portaria n. ${ }^{\circ}$ 2.982/2009 do Ministério da Saúde, quais sejam: i) imprescindibilidade ou necessidade do medicamento, assim como da ineficácia, para o tratamento da moléstia, dos fármacos fornecidos pelo SUS; ii) incapacidade financeira do paciente; e, iii) registro do medicamento na Anvisa.

Como se vê, também o Judiciário tem agido no sentido de que haja coerência e objetividade na concessão do bem da vida.

\section{A JUDICIALIZAÇÁO DA SAÚDE}

Oportuno salientar que a separação de poderes na obra de Montesquieu deve ser analisada ponderando o ativismo judicial e a figura do legislador democrático. Nesse sentido, é salutar, desde logo, clarificar a discussão em torno da impossibilidade de se invocar o princípio da separação dos poderes com o intuito da não efetivação dos direitos fundamentais sociais, aí se incluindo o direito à saúde.

Canela Junior enfrenta a questão, enaltecendo a independência do Poder Judiciário:

Não é possível a invocação do princípio da separação dos poderes para a não apreciação da pretensão do titular do direito fundamental social. Como já ressaltado, o Poder Judiciário, durante o exercício do controle de constitucionalidade, não interfere na esfera exclusiva de atribuição das demais formas de expressão do poder estatal por que atua exclusivamente no âmbito jurisdicional. (...) Por outro lado, o princípio da separação de poderes não pode ser utilizado para justificar a violação dos objetivos do Estado, aos quais todas as formas de expressão do poder estatal estão vinculadas. (...) Considera-se imparcial um Poder Judiciário que, não influenciado pelas vicissitudes político-partidárias, vincula-se completamente aos objetivos do 
Estado. Como um dos objetivos fundamentais do Estado é a efetivação da igualdade substancial, ex vi do disposto no art. $3^{\circ}$ da Constituição Federal, o Poder Judiciário demonstra toda a sua imparcialidade e Independência ao efetivar, mediante prestação jurisdicional, os direitos fundamentais, em especial os sociais. (...) Ao contrário do que reza a lógica da "reserva do possível", é a sentença judicial transitada em julgado que integrará o orçamento, obrigando o Estado a reajustar receitas e despesas, a fim de que os seus objetivos fundamentais sejam efetivamente atingidos. Este é, sem dúvida, o melhor alcance social que o Poder Judiciário poderia dar às suas decisões, na esteira do comando contido no art. $5^{\circ}$ da LINDB, em especial no caso de países subdesenvolvidos, em relação aos quais a opressão econômica e a miséria dos povos atingem patamares alarmantes. (CANELA JUNIOR, 2011, $94 / 95,98,109$ )

Diante da pretensão resistida, em relação à efetiva prestação estatal dos direitos sociais básicos, principalmente ao direito à saúde, e da recusa por parte do Estado, o caminho que resta para atender às suplicas do cidadão é o ingresso no Judiciário, e.g., para a disponibilização de leitos nos hospitais, realização de tratamentos ou intervenções cirúrgicas, ou fornecimento gratuito dos medicamentos. Situações essas que fazem parte do cotidiano dos operadores do direito.

Ademais, há de se reconhecer que a especificidade do sistema político está no tipo de comunicação que ele produz, ou seja, a comunicação do poder. De acordo com a teoria luhmanniana, a política é um sistema de comunicação operacionalmente fechado, autorreferente e autopoiético. $\mathrm{O}$ sistema político, bem como o do direito produzem operações sociais específicas, operações essas que promovem sua diferenciação social, cujo acoplamento estrutural entre os sistemas político e jurídico se dá através da Constituição Federal.

Nesse sentido:

A partir da dicotomia comunicativa (governo/oposição), o sistema político pode distribuir alternativas de decisão entre o governo e a oposição, em que as decisões políticas coletivamente vinculantes são tomadas pelo governo, ao passo que as ideias sobre alternativas possíveis de decisão passam a ser consideradas pela oposição (LUHMANN, 2005, p. 487). Assim, o governo decide e a oposição serve como referência reflexiva sobre essa decisão, mostrando outras possibilidades que o governo poderia tomar, possibilitando refletir sobre a decisão tomada pelo governo. A oposição, ao contrário do que acredita o senso comum, não deve se opor a toda decisão tomada pelo governo, ela deve mostrar as alternativas que não foram tomadas com o intuito de gerar reflexão sobre a decisão tomada pelo governo. (ROCHA; BAHIA, 2016, p. 75/76)

A partir das citações acima, pode-se observar que a atuação do magistrado é das mais difíceis, no que se refere aos requerimentos de efetivação do direito social fundamental, porquanto a realidade de determinadas administrações públicas poderá resultar num óbice material para a concretização da própria decisão judicial. O que não deveria ocorrer, a bem da verdade. 


\section{A QUESTÃO ORÇAMENTÁRIA}

Os Instrumentos de Planejamento e Orçamento, nos termos da CF/88, consistem em PPA, LDO e LOA.

O PPA, com vigência de quatro anos, tem como função estabelecer as diretrizes, objetivos e metas de médio prazo da administração pública. Cabe à LDO, anualmente, enunciar as políticas públicas e respectivas prioridades para o exercício seguinte. Já a LOA tem como principais objetivos estimar a receita e fixar a programação das despesas para o exercício financeiro.

Dito isso, a Carta Magna indica o caminho a ser percorrido, ou seja, o legislador constituinte estabeleceu que as normas fundamentais têm aplicabilidade imediata e eficácia plena, de modo que o orçamento se presta, exatamente, a dar cumprimento a esse comando constitucional. Qualquer postura diversa do administrador público é pura tergiversação.

Nesse sentido:

[...] o princípio da dignidade humana é aquele que qualifica o homem como o único ser dotado de valor não-relativo. Bem por isso, na esfera do mínimo vital, porquanto inerente à noção de dignidade humana, não há como mitigar-se, vale dizer, relativizar-se a noção de dignidade com base em previsões orçamentárias. (NUNES JUNIOR, 2009, p. 190)

Anote-se que a Constituição Federal é pródiga em assentar disposições sobre o direito à saúde. À guisa de exemplificação, cite-se o artigo $6^{\circ}$, que estabelece que a saúde compõe um direito social. No artigo $7^{\circ}$, outros dois incisos referem-se à saúde: o IV, determina que o salário mínimo deverá ser capaz de atender as necessidades vitais básica do trabalhador e às de sua família, inclusive a saúde; já o inciso XXII, prescreve a redução dos riscos inerentes ao trabalho, por meio de normas de saúde, higiene e segurança. Os artigos 23, e 24, XII, tratam da competência comum e concorrente que a União, os Estados, o Distrito Federal e os Municípios detêm para garantir a defesa e efetivação do direito à saúde, legislando sobre ela. 0 artigo 34, inciso VII, alínea "e" e 35, inciso III, abordam a possibilidade de a União intervir nos Estados e Municípios quando não for aplicado o mínimo exigido da receita resultante de impostos estaduais, compreendida a proveniente de transferências, na manutenção e desenvolvimento do ensino e nas ações e serviços públicos de saúde. Depreende-se do artigo 196 que a saúde é considerada direito de todos e dever do Estado, garantido mediante políticas sociais e econômicas que visem à redução do risco de doença e de outros agravos e ao acesso universal e igualitário às ações e serviços para sua promoção, proteção e recuperação.

Dessa forma, o direito à saúde, tanto física quanto mental, é essencial ao direito à vida que deve ser ofertado por todos os entes federativos através de políticas de tratamento e de prevenção, assistência médica, psicológica e jurídica, garantindo à sociedade a efetividade desse direito. Noutras palavras, o direito à saúde deve observar o princípio da igualdade material, que considera o caso concreto, bem como o mínimo existencial e a dignidade da pessoa humana.

Todavia, erroneamente, invoca-se a necessidade de se fazer escolhas - trágicas, aliás, como se diz -, a fim de que o princípio da reserva do possível, que se pauta na necessidade- 
-possibilidade (repita-se - que não guarda relação alguma entre o preconizado pelo ordenamento brasileiro e o pedido de acesso universal ao ensino público superior - no caso alemão), respeite os princípios da razoabilidade e da proporcionalidade, evitando que, para um medicamento de alto custo, a justiça não o conceda à apenas um indivíduo, em detrimento de um sem número de outros.

Nos termos da Lei 8.080/1990 e da 8.142/1990, o Sistema Único de Saúde deve ser o garantidor do direito à saúde, por meio da criação de uma política descentralizada e solidária, bem como disponibilizar hospitais e postos de saúde e outros meios que promovam o atendimento populacional, priorizando as ações preventivas, nos moldes da Magna Carta de 1988, devendo informar a população acerca de seus direitos e dos riscos à saúde.

Ora, feitas essas considerações, não se pode admitir que o órgão julgador seja benevolente com o devedor - no caso, o próprio Estado, definitivamente, não. Deixar de condenar, porque o demandado carece de patrimônio para satisfazer a obrigação é, no mínimo, agir por sentimentos benignos, como se disse.

Osvaldo Canela Junior dá um bom exemplo do que essa prática representaria, acentuando que o Poder Judiciário deve sim interferir no orçamento público:

Durante a fase declaratória do direito, portanto, não é dado ao órgão jurisdicional absorver a questão econômico-financeira para paralisar sua atividade. Isto representaria, em comparação com o plano privado, a esdrúxula figura na qual o devedor não seria condenado à reparação do dano, porque não dispõe de patrimônio suficiente para o adimplemento futuro do título executivo judicial. Se o patrimônio do Estado não é suficiente para o adimplemento completo de suas obrigações constitucionais, abre-se o caminho para duas soluções possíveis: a) aplicação do princípio da proporcionalidade na utilização dos recursos existentes, no caso de concessão de tutelas de urgência; ou, b) o ajuste orçamentário para o cumprimento da sentença transitada em julgado. (...) Orçamento, assim como qualquer ato estatal, deve estar estritamente vinculado aos objetivos inscritos no art. $3^{\circ}$ da Constituição Federal. Tal afirmação é consentânea com o pressuposto inarredável de que os fins do Estado somente poderão ser efetivamente atingidos por meio da utilização dos dinheiros públicos. (...) Do ponto de vista do Estado social, o orçamento não pode ser óbice à concessão dos direitos fundamentais sociais, mas seu instrumento de realização. (...) Conclui-se, pois, que a interferência do Poder Judiciário no orçamento público não somente é permitida, como igualmente obrigatória nas hipóteses de violação dos direitos fundamentais sociais. (destaques acrescentados) (CANELA JUNIOR, 2011, $103,107 / 108,111$ )

Observe-se com agudeza de detalhe, conforme assevera o autor, que jamais o aplicador da lei deverá se abster de sancionar o Estado inadimplente, sob o infeliz fundamento de que o devedor se encontra com seu passivo a descoberto e, por isso, não reúne condições de adimplir a obrigação.

Por certo que os mais incautos defenderão posicionamento contrário, sob o argumento de que a peça orçamentária serviria justamente para delimitar os gastos públicos. Todavia, a Constituição da República, de 1988, a esse respeito, ou seja, quando se trata de direitos fundamentais, não deixa margem para discricionariedades. Noutras palavras: cumpra-se a Lei Maior, sem delongas. 0 resto é resto. 
Todavia, oportuno salientar que o legislador constituinte, sob o discurso de um rigoroso ajuste fiscal levou a efeito o que se tornou a EC 95/2016 - a famigerada PEC do teto de gastos - trazendo nefastos cerceamentos aos direitos fundamentais, que não podem (ou não poderiam) estar à mercê de contingências políticas e econômicas, notadamente aos da saúde, tão sublime e expressamente consagrados no art. 196 do texto constitucional.

Ricardo Antunes (2018, p. 293) nos dá a exata dimensão da verdadeira razão de ser da norma: "garantir o superávit primário necessário para a remuneração do sistema financeiro por meio dos juros da dívida pública, esse sim um dos verdadeiros flagelos que assolam o país". Naturalmente, não se tem a pretensão de se debruçar sobre a questão econômica que envolve a emenda, mas tão somente abordá-la com o propósito de demonstrar o quanto foi maculado o dirigismo constitucional.

Como se vê, a imposição de limite de gastos na área da saúde e a chancela do descumprimento da Constituição, calcado no modelo germânico, sob a rubrica da "reserva do possível" que, como já se disse, nada tem de relação com a situação aqui exposta e debatida é, no mínimo, infidelidade às opções do legislador constituinte. Seria o equivalente a garantir direitos fundamentais sociais, desde que a burra esteja cheia, o que significa dizer, na prática, sem qualquer vinculação jurídica.

\section{OS CONTRATEMPOS DO DISCURSO CONSEQUENCIALISTA}

Decorridos 30 anos da promulgação da Constituição de 1988, não bastassem as intempéries que rondam os direitos fundamentais, urge trazer à baila a recente publicação da Lei n. ${ }^{0}$ 13.655/2018 que, dentre outras alterações legislativas à LINDB, impôs ao magistrado (art. 20, LINDB) ${ }^{3}$ - excerto que nos interessa no presente estudo - a obrigatoriedade de considerar as "consequências práticas" ao proferir sua decisão, o que nos leva a fazer indagações no seguinte sentido: i) qual seria essa análise prévia das consequências jurídicas práticas da decisão? ii) estaria o julgador obrigado a avaliar, e.g., qual o impacto da decisão no SUS? Há de se arriscar em dizer que seria um verdadeiro exercício de futurologia, enfim.

Naturalmente que esse novo dispositivo não proíbe que se decida com base em valores jurídicos abstratos. No entanto, todas as vezes em que se decidir com base em valores jurídicos abstratos, deverá ser feita uma análise prévia de quais serão as consequências práticas dessa decisão, em outras palavras, o art. 20 da LINDB introduz a necessidade de o órgão julgador considerar um argumento metajurídico no momento de decidir.

Indubitavelmente, verifica-se uma flagrante tentativa de mitigar a força normativa dos princípios. Ora, a própria Constituição da República é repleta de "valores abstratos". São inúmeros os exemplos, eis alguns deles: "dignidade da pessoa humana" (art. $\left.1^{\circ}, \mathrm{III}\right)$; "valores sociais do trabalho e da livre iniciativa" (art. 1, IV); "moralidade" (art. 37, caput); "bem-estar e a justiça sociais" (art. 193); "meio ambiente ecologicamente equilibrado" (art. 225). 
Com base na força normativa dos princípios constitucionais, o Poder Judiciário, nos últimos anos, condenou o Poder Público a implementar uma série de medidas destinadas a assegurar direitos que estavam sendo desrespeitados, conforme se depreende do RE 429.903/RJ, que condenou a Administração Pública a manter estoque mínimo de determinado medicamento, a fim de que se evitasse novas interrupções no tratamento de doenças graves. De igual maneira, pelo RE 592.581/RS, o Poder Público foi condenado a realizar obras emergenciais em estabelecimento prisional.

Como se vê, essas decisões foram proferidas com fundamento em princípios constitucionais, ou seja, com base em "valores jurídicos abstratos". O que o legislador pretendeu, portanto, foi, indiretamente, tentar tolher o ativismo judicial em matérias envolvendo implementação de direitos.

É como se o legislador introduzisse uma condicionante para a força normativa dos princípios: eles somente podem ser utilizados para fundamentar uma decisão se o julgador considerar "as consequências práticas da decisão". Trata-se, portanto, de uma reação retrógrada à força normativa dos princípios constitucionais.

Souza (2018, p. 126/127) faz severa crítica às inovações trazidas pela Lei n. ${ }^{\circ} 13.655$, de 25 de abril de 2018, justamente por entender que a regra insculpida no art. 20 da LINDB mal esconde uma certa forma de idealismo, como se ao juiz fosse dado entrever um leque completo das consequências possíveis resultantes de sua decisão, o que significa dizer que teria de fazer um verdadeiro exercício de futurologia:

Quando se diz que o juiz não deve decidir com base em valores abstratos (artigo 20), busca-se colocar um freio na argumentação retórica, discurso que se vale de lugares comuns (topois) e fórmulas consagradas pelo uso. Isto explica, aliás, as recentes inovações do Código de Processo Civil (LF no 13.105/15), mais particularmente a razão de ser da norma do artigo 489, $\S 10$, I a III (SOUZA, 2016). (...) é certo que cada julgador tem sua cosmovisão, de forma que o responsável pelo "controle judicial do controle administrativo" fará estimativas que se põem de acordo com sua visão de mundo, enquanto que o responsável pelo controle administrativo valorará a necessidade e adequação da invalidação de atos, contratos, ajustes, processos ou normas administrativas, tanto quanto das medidas impostas, de acordo com uma visão de mundo própria. (SOUZA, 2018, 126/127)

Morais e Zolet demonstram preocupação com o advento das alterações inseridas na LINDB, notadamente em relação à (in)segurança jurídica:

Sabe-se, com base nas disposições normativas da LINDB, da possibilidade de tomada de decisão por meio da consideração das consequências práticas da decisão. Contudo, resta saber qual o volume certo, necessário ou suficiente de considerações a serem levadas em onta pelos julgadores no âmbito das suas decisões. Em decorrência disso, espera-se que o consequencialismo não seja apenas um novo traje para vestir um velho hábito: arbitrariedade. (MORAIS; ZOLET, 2018, p. 518),

Marçal Justen Filho de outro lado, faz um mea-culpa:

Toda decisão fundada em normas gerais e abstratas pressupõe um processo de ponderação relacionado de modo inafastável com o universo fático existente. Isso exige considerar as consequências práticas de uma decisão, 
inclusive para evitar a consumação de danos irreparáveis aos próprios valores invocados como fundamento para decidir. (JUSTEN FILHO, 2018, p. 23),

Não obstante entendimento contrário, não seria demais salientar que a nova LINDB traz, implicitamente, margem para que direitos sejam afastados, com fundamento em consequências de caráter puramente econômico, batizado de "consequências práticas". Em suma, um verdadeiro ataque aos direitos fundamentais.

\section{CONSIDERAÇÓES FINAIS}

Os direitos à saúde seguem precários, frágeis e cambaleante, São alvos de constantes ataques e achaques - à vista da aplicação enviesada da teoria da reserva do possível, cujo modelo alemão em pouco se assemelha aos direitos fundamentais aqui debatidos.

A EC 95/2016, por sua vez, instituiu novo regime fiscal, impactando direta e negativamente as ações e serviços públicos de saúde. Não bastasse isso, o legislador ordinário, em recente alteração legislativa à LINDB - notadamente com a inclusão do art. 20 -, fez materializar uma nova investida contra os direitos fundamentais, ao estabelecer que não se decidirá sem levar em conta as consequências práticas da decisão, numa flagrante tentativa de mitigação da força normativa dos princípios, com o objetivo inconfessável de frear o ativismo judicial. Ora, não se pode olvidar de que a área de eficácia inconcretizável pelo Poder Judiciário é tão somente a metajurisdicional, que está sob os holofotes dos Poderes Legislativo e Executivo, cuja atuação do Judiciário é a de emprestar [ou não] mera validade jurídica à norma. De outro lado, o núcleo essencial - aí se incluindo os direitos fundamentais à saúde -, é justamente aquela área em que o Poder Judiciário age pela efetiva realização do direito, almejando a eficácia social da norma.

A efetivação dos direitos fundamentais, no que tange ao direito à saúde, nos paradigmas da Constituição da República de 1988, deve ser assegurada pelo Estado, sendo o Poder Público responsável pela implementação da norma.

$\mathrm{Na}$ resolução desses impasses entre o direito à saúde, à vida, à dignidade da pessoa humana e a realidade financeira do Estado, há um conflito entre normas constitucionais, tornando-se necessário recorrer aos princípios previstos na própria Constituição Federal.

Pode-se inferir que a imposição legal de que os juízes deverão predizer uma gama de consequências advindas de suas decisões e diminuir a força normativa dos princípios. É frear a atuação do juiz quando, na verdade, a própria constituição determina e espera que se faça justamente o contrário.

Cabe ao exegeta, de maneira acurada, ter em conta os fundamentos inerentes à teoria do mínimo existencial, ou seja, aquilo que está relacionado à parte nuclear dos direitos - de aplicação imediata - bem como da ponderação entre os princípios, adequando o caso concreto às atuais necessidades sociais, os ditames constitucionais e as prementes necessidades daqueles que postulam pelo cumprimento de seus direitos essenciais. 


\section{REFERÊNCIAS}

ALEXY, Robert. Teoria dos direitos fundamentais. Tradução de: Virgílio Afonso da Silva. São Paulo: Malheiros, 2008

ANTUNES, Ricardo. O privilégio da servidão: O novo proletariado de serviços na era digital. São Paulo: Boitempo, 2018

BRASIL. Constituição (1988). Constituição da República Federativa do Brasil. Disponível em: http://www.planalto. gov.br/ccivil_03/constituicao/ConstituicaoCompilado.htm. Acesso em: 30 jun. 2019.

BRASIL. Decreto-lei n 4.657, de 04 de setembro de 1942. Decreto-lei 4.657. Disponível em: http://www.planalto. gov.br/ccivil_03/decreto-lei/Del4657compilado.htm. Acesso em: 10 abr. 2019.

BRASIL. Lei Ordinária n 13.655, de 25 de abril de 2018. Lei 13.655. Disponível em: http://www.planalto.gov.br/ ccivil_03/_ato2015-2018/2018/lei/L13655.htm. Acesso em: 10 abr. 2019.

BRASIL. Lei Ordinária nº 8.080, de 19 de setembro de 1990. Lei 8.080. Disponível em: http://www.planalto.gov.br/ ccivil_03/Leis/L8080.htm. Acesso em: 10 abr. 2019.

BRASIL. Lei Ordinária n 8.142, de 28 de dezembro de 1990. Lei 8.142. Disponível em: http://www.planalto.gov.br/ ccivil_03/Leis/L8142.htm. Acesso em: 10 abr. 2019.

BRASIL. Portaria n 2.982, de 26 de novembro de 2009. Portaria 2.982. Disponível em: http://bvsms.saude.gov.br/ bvs/saudelegis/gm/2009/prt2982_26_11_2009_rep.html. Acesso em: 26 nov. 2019.

CANELA JUNIOR, Osvaldo. Controle Judicial de Políticas Públicas. São Paulo: Saraiva, 2011.

COSTA, Ilton Garcia da; PIEROBON, Flavio; SOARES, Eliane C. A Efetivação do Direito ao Saneamento Básico no Brasil: Do Planasa ao Planasb. Revista Meritum, Belo Horizonte, v. 13, n.2, p. 335-358, 2018.

COSTA, Ilton Garcia; GOES, Winnicius Pereira. A Diretiva 2014/24/UE como Guia de Contratualizações Sustentáveis de Políticas Públicas Sociais. Novos Estudos Jurídicos (ONLINE), Itajaí SC, v. 21, p. 656-690, 2016.

COSTA, Ilton Garcia; GONÇALVES, Aline M. Da Sociedade Antiga à Sociedade Política e a Funcionalidade do Direito. Nomos Fortaleza, v. 36, p. 205-224, 2016

COSTA, Ilton Garcia; MERHEB, Marcos P. S. B.; SANTOS, Sandra F. B. Derecho a la Salud y Suministro de Medicamentos - Desafíos del Estado Democratico y Social de Derecho ante las Garantias Constitucionales. Revista de Derecho y Câmbio Social, Lima Peru v. 49, p. 1-30, 2017.

COSTA, Ilton Garcia; ZOLANDECK, Willian Cleber. A Responsabilidade Civil do Estado por Erro Judiciário. Revista Jurídica (FIC), Curitiba. v. n28. v1, p. 210-229, 2012.

GOES, Guilherme Sandoval. Direito Constitucional Avançado. Rio de Janeiro: Seses, 2018.

JUSTEN FILHO, Marçal. Art. 20 da LINDB - Dever de transparência, concretude e proporcionalidade. Revista de Direito Administrativo, Rio de Janeiro, p.13-41, 23 nov. 2018. Disponível em: http://bibliotecadigital.fgv.br/ojs/ index.php/rda/article/view/77648/74311. Acesso em: 23 out. 2019.

MORAIS, Fausto Santos de; ZOLET, Lucas. A nova Lindb e os Problemas da Argumentação Consequencialista. Revista Jurídica - Unicuritiba, Curitiba, v. 53, n. 4, p.497-523, out./dez. 2018. Disponível em: http://revista. unicuritiba.edu.br/index.php/RevJur/article/view/3229/371371745. Acesso em: 23 out. 2019.

NOVELINO, Marcelo. Direito Constitucional. 5. ed. São Paulo: Método, 2011.

NUNES JUNIOR, Vidal Serrano. A cidadania social na Constituição de 1988: Estratégias de positivação e exigibilidade judicial dos direitos sociais. São Paulo: Verbatim, 2009.

ROCHA, Paulo Henrique Borges da; BAHIA, Alexandre Gustavo Melo Franco. Sistema Político Municipal: um estudo sobre as eleições legislativas em Divinópolis a partir de Niklas Luhmann. Argumenta Journal Law, Jacarezinho, n. 23, p.71-94, jan. 2016. Disponível em: http://seer.uenp.edu.br/index.php/argumenta/article/view/622. Acesso em: 06 nov. 2019. 
RUSSO, Thiago Nogueira; LEHFELD, Neide Aparecida de Souza. Controle jurisdicional das políticas públicas que visam concretizar o direito à saúde. Argumenta Journal Law, Jacarezinho, n. 23, p.313-331, jan. 2016. Disponível em: http://seer.uenp.edu.br/index.php/argumenta/article/view/628. Acesso em: 11 abr. 2019.

SARLET, Ingo Wolfgang. A eficácia dos direitos fundamentais: Uma teoria geral dos direitos fundamentais na perspectiva constitucional. 11. ed. Porto Alegre: Livraria do Advogado, 2012.

SILVA, Delmo Mattos; RAMOS, Edith M. B. O princípio do resgate e a questão do seguro hipotético em Dworkin no âmbito do direito à saúde: possibilidades e limites do livre mercado e a aplicação da justiça. Revista Meritum, Belo Horizonte, v. 13, n. 1, p. 263-281, 2018.

SOUZA, Luiz Sergio Fernandes de. As recentes alterações da LINDB e suas implicações. Revista Jurídica da Escola Superior do Ministério Público de São Paulo, São Paulo, v. 14, n. 2, p.123-132, jul./dez. 2018. Disponível em: http://www.esmp.sp.gov.br/revista_esmp/index.php/RJESMPSP/article/view/366/340340384. Acesso em: 23 out. 2019.

TIESSI, Bruna Geovana Fagá; COSTA, Ilton Garcia da. Relação fiscal e sua efetivação a partir dos princípios constitucionais que garantem os direitos fundamentais. Revista Jurídica - Unicuritiba, Curitiba, v. 3, n. 32, p.163-180, 2013. Disponível em: http://revista.unicuritiba.edu.br/index.php/RevJur/article/view/683/509. Acesso em: 06 nov. 2019.

Recebido/Received: 08.06.2020.

Aprovado/Approved: 26.09.2020. 